\title{
Occurrence of chilli veinal mottle virus in Lycopersicon esculentum in Jiangxi Province in China
}

\author{
Yong-Hui Liao ${ }^{1}$ - Gen-He He ${ }^{1} \cdot$ Zhao-Lin $\mathrm{Ji}^{2} \cdot$ Feng Zhu ${ }^{2}$ \\ Received: 5 July 2019 / Accepted: 30 July 2019 / Published online: 8 August 2019 \\ (C) Società Italiana di Patologia Vegetale (S.I.Pa.V.) 2019
}

Keywords Chilli veinal mottle virus $($ ChiVMV) Lycopersicon esculentum · China

In September of 2018, virus-like symptoms such as mottling, mosaic, and narrowing were observed on tomato (Lycopersicon esculentum) plants in Pengze County, Jiangxi Province, east China. Three symptomatic tomato leaf samples were collected. These samples were assayed by western blotting using polyclonal antiserum to cucumber mosaic virus (CMV), tobacco mosaic virus (TMV), chilli veinal mottle virus (ChiVMV) (Zhu et al. 2013, 2014). Two of three samples were positive for ChiVMV. Next, reverse transcription (RT)-PCR was performed to confirm the occurrence of ChiVMV using primers identical to nucleotides 8969 to 8985 (ChiVMV-F: 5'-GGAT TGATGGTTTGGTG-3') and complementary to nucleotides 9202 to 9219 (ChiVMV-R: 5'-CGCGCTAATGACATATCG3 ), which were designed to amplify a partial coat protein gene region of ChiVMV (GenBank accession No. GQ981316). The expected $251 \mathrm{bp}$ amplicon was amplified from the two symptomatic leaf samples that were positive for ChiVMV in western blotting. The PCR products were cloned and sequenced (MK977725). BLASTN analysis revealed that the consensus sequence had $96.8-98.4 \%$ identity to 14 ChiVMV sequences available in GenBank (DQ925446, GQ981316, HQ317868, KC711055, KC693766, KX867924, KX867925, KX867926, KX867927, MF537352, HQ317867, KC711056, KF738253,

Yong-Hui Liao and Gen-He He contributed equally to this work.

Feng Zhu

zhufeng@yzu.edu.cn

1 School of Life Sciences, Key Laboratory of Biology Diversity and Ecological Engineering of Jiangxi Province, Jinggangshan University, Ji'an 343009, China

2 College of Horticulture and Plant Protection, Yangzhou University, Yangzhou 225009, Jiangsu, China
KX867928). An isolate of ChiVMV from symptomatic tomato was mechanically transmitted to Nicotiana tabacum and tomato, in which infection was confirmed by RT-PCR with total RNA extracted from leaves and the aforementioned primers. To our knowledge, this is the first report of ChiVMV naturally infecting tomato in Jiangxi Province in China.

Acknowledgements This study was supported by the Qing Lan Project of Yangzhou University and the earmarked fund for Modern Agroindustry Technology Research System (CARS-30-3-02).

\section{Compliance with ethical standards}

Conflict of interest The authors declare that they have no conflict of interest.

Research involving human participants and/or animals This article does not contain any studies with human participants or animals performed by any of the authors.

Informed consent This manuscript is new and not being considered elsewhere. All authors have approved the submission of this manuscript.

\section{References}

Zhu F, Zhang P, Meng YF, Xu F, Zhang DW, Cheng J, Lin HH, Xi DH (2013) Alpha-momorcharin, a RIP produced by bitter melon, enhances defense response in tobacco plants against diverse plant viruses and shows antifungal activity in vitro. Planta 237:77-88

Zhu F, Xi DH, Deng XG, Peng XJ, Tang H, Chen YJ, Jian W, Feng H, Lin $\mathrm{HH}$ (2014) The Chilli veinal mottle virus regulates expression of the Tobacco mosaic virus resistance gene $N$ and jasmonic acid/ethylene signaling is essential for systemic resistance against Chilli veinal mottle virus in tobacco. Plant Mol Biol Report 32:382-394

Publisher's note Springer Nature remains neutral with regard to jurisdictional claims in published maps and institutional affiliations. 